\title{
Marital Satisfaction, Depression, and Attributions: A Longitudinal Analysis
}

\author{
Frank D. Fincham and Thomas N. Bradbury
}

\begin{abstract}
This study examined the longitudinal relation between causal attributions and marital satisfaction and tested rival hypotheses that might account for any longitudinal association found between these variables. Data on attributions for negative partner behaviors, marital satisfaction, depression, and self-esteem were provided by 130 couples at 2 points separated by 12 months. To the extent that spouses made nonbenign attributions for negative partner behavior, their marital satisfaction was lower a year later. This finding was not due to depression, self-esteem, or initial level of marital satisfaction, and also emerged when persons reporting chronic individual or marital disorder were removed. Results support a possible causal relation between attributions and marital satisfaction.
\end{abstract}

In the past decade, researchers have expended considerable effort in trying to understand the role of attributions in close relationships. Numerous studies now document an association between relationship satisfaction and attributions for relationship events (for reviews, see Bradbury \& Fincham, 1990; Harvey, 1987; Weiss \& Heyman, 1990). Compared to happy partners, distressed partners tend to locate the causes of negative relationship events in the other person and to see the causes of those events as stable and global; the inverse pattern of findings is obtained for positive events. Although this research was largely motivated by conceptual analyses that emphasized the effects of attributions on marital satisfaction (e.g., Baucom, 1987; Epstein, 1982), surprisingly few studies have addressed the causal status of attributions in close relationships. In addition, little attempt has been made to investigate rival explanations for the attribution-satisfaction link, leaving open the possibility that this association is an artifact of unmeasured variables. To address the causal status of attributions, we investigated the longitudinal association between attributions and marital satisfaction. A second purpose of this study is to examine factors that might account for any concurrent and longitudinal associations found between these two variables.

\section{Are Attributions Causally Related to Marital Satisfaction?}

It is widely assumed that causal attributions for marital events maintain, and perhaps initiate, marital distress. This effect may be direct or it may be mediated by the assumed

Preparation of this article was supported by a Faculty Scholar Award from the William T. Grant Foundation and Grant R01 MH44078-01 from the National Institute of Mental Health awarded to Frank D. Fincham, and by Grant F31 MH 09740-01 from the National Institute of Mental Health awarded to Thomas N. Bradbury. We thank Susan Campbell and Ben Karney for their helpful comments on an earlier version of this article.

Correspondence concerning this article should be addressed to Frank D. Fincham, Psychology Department, University of Illinois, 603 East Daniel, Champaign, Illinois 61820, or to Thomas N. Bradbury, Psychology Department, University of California, 405 Hilgard Avenue, Los Angeles, California 90024. effects of causal inferences for partner behavior on subsequent responses to the behavior (for an integrative model relating attributions, behavior, and satisfaction, see Bradbury \& Fincham, 1990). Few data have been collected to examine the effect of attributions on satisfaction, a circumstance that may be due, in part, to constraints on conducting experiments in this area.

In one of the few experimental studies conducted, Seligman, Fazio, and Zanna (1980) used dating couples to show that making salient the extrinsic causes for being in the relationship resulted in lower scores on Rubin's (1970) Love Scale. However, the attribution manipulation did not affect scores on Rubin's Liking Scale or global ratings of love and liking. These findings are promising but need to be interpreted cautiously in view of their inconsistency and a failure to replicate them (Rempel, Holmes, \& Zanna, 1985). In addition, they contrast with the results of marital therapy outcome research showing that supplementing standard treatments with attributionally oriented interventions does not enhance marital satisfaction more than standard interventions (e.g., Baucom, Sayers, \& Sher, 1990; for a review see Fincham, Bradbury, \& Beach, 1990). ${ }^{1}$

As Olson and Ross (1985) noted, perhaps the most viable means of investigating a possible casual relation between attributions and marital satisfaction is to collect longitudinal data. The two longitudinal studies conducted to date suggest that attributions may indeed influence relationship satisfaction. Fletcher, Fincham, Cramer, and Heron (1987) found that the extent to which dating partners $(76 \%$ of the sample were women) attributed the maintenance of the relationship to themselves versus their partner predicted happiness with the relationship 2 months later after initial happiness had been statistically controlled. In a similar vein, Fincham and Bradbury (1987) assessed marriages at two points separated by a 12-month interval and found that initial attributions predicted later marital satisfaction. Nonetheless, these findings must also

\footnotetext{
${ }^{1}$ The results of intervention studies are perhaps not surprising in view of their limitations. These include the failure to document the manipulation of attributions, the limited nature of the attribution interventions, and, most importantly, the power of the studies to detect differences between treatments (see Fincham, Bradbury, \& Beach, 1990).
} 
be viewed with caution because only one of two relevant analyses revealed a significant longitudinal relation in Fletcher et al.'s study and the longitudinal association in Fincham and Bradbury's study was obtained for wives but not husbands. The latter finding is consistent with the hypothesis that women are barometers of relationship well-being (Ickes, 1985).

Available data relevant to assessing the indirect effects of attributions on satisfaction (e.g., by demonstrating the effect of attributions on behavior) are similarly limited. Experimental (Fincham \& Bradbury, 1988) and correlational data document an association between attributions and observed behavior (Bradbury \& Fincham, 1991; Doherty, 1982; Miller, Lefcourt, Holmes, Ware, \& Saleh, 1986; Sillars, 1985). However, in Doherty's study the attribution-behavior link was found only for women. Although a reliable association appears to exist between attributions and behavior, additional data are needed to understand more precisely the causal nature of this relation.

In summary, several lines of evidence are consistent with the hypothesis that attributions influence relationship satisfaction. However, both within and across studies, the results are not uniformly supportive of this hypothesis. Even if these studies did show a consistent effect, it might be artifactual because of unconsidered variables. This points to the importance of rival hypotheses for the attribution-satisfaction link, a topic to which we now turn.

\section{Is the Attribution-Satisfaction Association an Artifact?}

In the discussion below, we consider two important threats to the validity of past research on attributions in relationships. First, the consistent relation obtained between attributions and satisfaction may simply reflect their joint association with some third variable. Second, the longitudinal association could result from the failure to exclude from the sample persons with chronic disorders.

\section{Depression and Self-Esteem}

In view of the association between attributions and depression (see Robins, 1988) and between depression and marital distress (see Beach, Sandeen, \& O'Leary, 1990), it is possible that depression accounts for the attribution-satisfaction link. Three studies have addressed this possibility. Fincham, Beach, and Bradbury (1989) conducted two studies that investigated wives' responsibility attributions. Unlike causal attributions, which pertain to who or what produced an outcome or event, responsibility attributions concern accountability for the outcome and determine liability for sanctions (for further discussion see Bradbury \& Fincham, 1990; Shaver, 1985). In their first study, Fincham et al. (1989) examined a community sample and found that when depression scores and responsibility attributions (indices comprising judgments of blame, motivation, and intent) were simultaneously entered into a regression equation, only the latter predicted marital satisfaction. The second study included wives with clinically diagnosed levels of depression and showed that the attributions of depressed and nondepressed wives who were maritally distressed did not differ but that both groups differed from happily married wives. Fletcher, Fitness, and Blampied (1990) found that, in dating couples, relationship happiness accounted for unique variance in spontaneous and elicited attributions when depression scores were statistically controlled.

Several factors need to be considered in evaluating the studies described above. First, none addressed the role of depression in the longitudinal relation between attributions and satisfaction. Second, the need to study both husbands and wives is self-evident. Third, because attributional models of depression pertain to causal attributions, this type of attribution requires further study; although Fletcher et al. (1990) examined causal attributions, they combined them with responsibility attribution dimensions to form an overall attribution index, and they omitted ratings of the self as causal locus from the index. The significance of this omission is addressed below.

Although attributional models of depression and of relationship satisfaction are similar in their predictions for stable and global attributions, they differ in the predictions they make for causal locus. According to these models, depressed spouses should view themselves as the cause of negative relationship events, whereas maritally distressed spouses should see their partners as the cause of such events. In each case the spouse makes nonbenign attributions that apply either to the self or to the partner and are likely to accentuate the impact of the negative event.

These differential predictions highlight a fundamental problem with the analysis of the locus dimension in prior relationship research. Specifically, self and partner have been used as endpoints in assessments of the locus dimension. This implies an inverse relation between the two loci that runs counter to data on this issue (e.g., Fincham, 1985; Taylor \& Koivumaki, 1976). Independent assessments that have been obtained typically have been analyzed separately. The problem with this practice is that spouses' responses are likely to be guided by the extent to which the partner is seen as the cause relative to the self. For example, a husband who locates the cause in his partner and does not see himself as a causal locus is likely to react differently to the partner's behavior than is a husband who similarly locates the cause in the partner but also sees himself as a cause of the behavior. In the latter case, the discounting principle should lead him to moderate his reactions to the partner's behavior. Alternatively, he may be more tolerant of such behavior to avoid possible censure for his own role in producing it. In light of such observations, Bradbury and Fincham (1990) have argued that future research must examine separate locus dimensions relative to one another. Therefore, in the present study we examine the utility of this comparative conception of causal locus.

A second variable that may account for the attribution-satisfaction link is self-esteem. The attribution pattern associated with depression has also been related to self-esteem (Ickes, 1988; Ickes \& Layden, 1978). Self-esteem, in turn, is widely thought to be influenced by marital quality, a viewpoint that has gained some empirical support. For example, receiving affirmation in a marital relationship has been related to higher levels of self-esteem (Vanfossen, 1986). To date, no data have been collected to test the hypothesis that self-esteem accounts for the attribution-satisfaction link.

Because loss of self-esteem is often a symptom of depression, it seems reasonable to ask whether the findings outlined above for studies of depression and attributions in marriage can be generalized to self-esteem. At least two factors caution against 
such generalizations. First, loss of self-esteem can occur independently of depression, suggesting that the correlation between the two constructs is likely to be moderate. Second, positive aspects of well-being, such as self-esteem, may have different correlates than negative aspects, such as depression (cf. Zautra \& Reich, 1983). Zautra, Guenther, and Chartier (1985) provided empirical support for this view that is particularly germane in the present context; they found that casual attribution dimensions relating to positive events correlated signifcantly with self-esteem but not with depression. In view of these observations, depression and self-esteem should not be considered to have equivalent relations with attributions, and as a consequence, we examine them separately in the present study.

Finally, several considerations point to a possible sex difference in the magnitude of the correlations involving depression, self-esteem and marital satisfaction, including the higher incidence of depression among wives than husbands (Gotlib \& McCabe, 1990) and the widespread belief that women value intimate relationships more than men (e.g., Fitzpatrick, 1988), that wives more commonly feel unappreciated by their spouses than do husbands (Noller, 1987), and that wives tend to be more self-critical than their husbands (Carver \& Ganellen, 1983). These considerations, together with the growing literature on gender differences in marriage (see Baucom, Notarius, Burnett, \& Haefner, 1990) and the studies noted earlier in which attribution findings obtained only for wives (Doherty, 1982; Fincham \& Bradbury, 1987), emphasize the importance of examining relations separately for husbands and wives.

\section{Chronic Disorder}

Depue and Monroe (1986) noted that, in life stress research, the most powerful predictor of subsequent disorder is prior disorder. Furthermore, they showed that most people who score high on measures of psychological distress in general population samples have stable disturbances and that this can lead to artifactual longitudinal relations between distress and its correlates. One means of addressing this problem is to statistically control for initial distress. However, this solution is less than optimal because longitudinal relations and the underlying processes that give rise to the relations may differ for chronic and acute psychological distress. For example, attributions may play different roles in the initiation of disorder than they do in the maintenance of disorder. A more desirable means of addressing such problems is to increase the homogeneity of the sample studied. Accordingly, in the present study we examined the effect of excluding persons with high disorder scores on the longitudinal relations studied.

\section{Overview}

The primary goal of our study was to examine the longitudinal relation between causal attributions and marital satisfaction. Such information is crucial for addressing the assumed casual relation between these two variables that is basic to theoretical analyses in this area and to attributionally oriented treatment outcome research. A second goal was to test rival hypotheses for any concurrent and longitudinal associations found between these two variables. Ruling out rival hypotheses is critical to understanding existing data that document a link between attributions and marital satisfaction. A final goal was to replicate findings concerning the correlates of marital satisfaction and to examine the longitudinal relation between depression and marital satisfaction. To address these goals, we collected data from married couples at two points 12 months apart.

\section{Method}

\section{Subjects}

We initially recruited 130 married couples through advertisements in local newspapers. Couples had been married an average of $9.4(S D=9.9)$ years and averaged $1.5(S D=1.6)$ children. Gross family income was $\$ 25,000-\$ 30,000$. Of the wives, $97 \%$ were White and $55 \%$ chose Protestant as their religious preference $($ Catholic $=19 \%$; other $=$ $17 \%$; no religious preference $=9 \%)$. Wives averaged $32.0(S D=9.8)$ years of age, $14.3(S D=2.2)$ years of education, and obtained a mean score of $111.1(S D=22.9)$ on the Marital Adjustment Test (MAT; Locke \& Wallace, 1959). Husbands were also predominantly White $(97 \%)$ and Protestant $(54 \%$; Catholic $=14 \%$; other $=17 \%$; no religious preference $=15 \%)$. Husbands averaged $34.0(S D=10.2)$ years of age, $14.5(S D=2.6)$ years of education, and a score of $110.4(S D=21.7)$ on the MAT.

At 12 months after the first phase of the study, we attempted to recontact couples, and obtained data from 106 couples. We conducted multivariate $t$ tests to examine whether spouses who provided data for the first phase of the data collection differed from those who provided data for both phases of the study. The two groups did not differ in terms of demographics or any of the variables investigated in the study, indicating that attrition did not bias the sample providing longitudinal data.

\section{Procedure}

At both phases of the project, couples received two sets of materials by mail, together with separate postage-paid return envelopes and a cover letter that thanked them for their participation in the project and instructed them on their task. They were asked to complete the materials independently and to seal the completed materials in separate envelopes before talking about the project. Couples were paid $\$ 15.00$ upon receipt of the completed materials.

\section{Measures}

Marital satisfaction. The MAT (Locke \& Wallace, 1959) is a widely used measure of marital satisfaction that yields a score ranging from 2 to 158 . It has adequate reliability (split half $=.90$ ) and discriminates between nondistressed spouses and spouses who have documented marital problems (Locke \& Wallace, 1959). Scores on this instrument also correlate with clinicians' judgments of marital discord (Crowther, 1985).

Depressive symptoms. We assessed depressive symptoms using the Beck Depression Inventory (BDI; Beck \& Beamesderfer, 1974). This scale reliably measures the severity of affective, cognitive, motivational, and physical (vegetative) symptoms of depression in nonpsychiatric samples (mean level of internal consistency over 15 samples = .81 , range $=.73$ to .92 ). The BDI correlates highly with clinical ratings and other measures of depression and differentiates depression from anxiety (Beck, Steer, \& Garbin, 1988).

Self-esteem. The Rosenberg (1965) Self-Esteem Scale is a 10-item measure that reliably assesses self-esteem (2-week test-retest reliability is .85$)$. This scale also correlates $(.56$ to .83$)$ with other similar measures and with clinical assessments of self-concept problems (Silber \& Tippett, 1965). 
Attributions. We assessed attributions for negative events because they appear to be related more consistently and more strongly to marital satisfaction than attributions for positive events (e.g., Fincham, Beach, \& Nelson, 1987; Baucom, Sayers, \& Duhe, 1989), they have been implicated in theoretical attempts to understand the negative behavior exchanges that are the hallmark of marital distress (Fincham \& Bradbury, 1991), and they are most relevant in the clinical context. The decision to focus on attributions for negative events was also guided by two well-established findings in the broader marital literature-that negative behaviors have a far greater impact on the marriage than positive behaviors, and that this impact occurs independently of positive events (see Weiss \& Heyman, 1990).

We used four common partner behaviors as stimuli to obtain attribution judgments ("Your wife/husband criticizes something you say," "Your wife/husband begins to spend less time with you," "Your wife/ husband does not pay attention to what you are saying," "Your wife/ husband is cool and distant"). We used hypothetical behaviors because of the advantages conferred by standard stimuli across spouses and because the pattern of responses to such behaviors is similar to that found for attributions for marital difficulties (Fincham \& Beach, 1988). The behaviors used as stimuli were selected to be common enough to permit virtually all spouses to imagine them occurring in their relationship.

For each partner behavior, we asked respondents to rate their agreement with attribution statements about three causal attribution dimensions. Two statements assessed causal locus and inquired about the extent to which the cause rested in the partner ("My husband's behavior was due to something about him [e.g., the type of person he is, the mood he was in]"), and rested in themselves ("My husband's behavior was due to something about me [e.g., what I said or did, the kind of person I am ]"). The remaining two questions assessed the stability and globality of causal dimensions, respectively. The stability item inquired about the extent to which the cause was likely to change ("The reason my husband criticized me is something that is not likely to change") and the globality item assessed the extent to which the cause affected other areas of the marriage ("The reason my husband criticized me is something that affects other areas of our marriage"). Spouses rated the statements after imagining that the stimulus behavior had just occurred in their marriage.

Ratings were made using a 6-point scale on which each scale point was labeled (ranging from disagree strongly to agree strongly) to make the task as concrete as possible. We summed responses to corresponding statements across the four stimulus events and computed coefficient alpha for each attribution dimension (partner locus: husbands = .70 , wives $=.63$; self locus: husbands $=.58$, wives $=.63$; stability: husbands $=.65$, wives $=.76 ;$ globality: husbands $=.78$, wives $=.75$ ). For the two locus dimension items, higher scores indicated that the respondent was more likely to locate the cause in the partner and in the self, respectively. Higher stability scores indicated that the cause was seen as more stable and higher globality scores reflected the perception that the cause was more global.

To examine partner attributions relative to self-attributions, we combined the responses to the two causal locus questions to obtain a single locus score by subtracting self-ratings from partner ratings (coefficient alpha, husbands $=.64$, wives $=.63$ ). Higher scores indicated that the spouse was more likely than the self to be viewed as the locus of the cause.

In the marital literature, hypotheses specific to individual attribution dimensions are rare (cf. Bradbury \& Fincham, 1990). Instead, the theoretical focus has been on responses across causal dimensions leading some investigators to use an overall composite index of attributions (e.g., Fincham \& Bradbury, 1987). Because there is some debate regarding the use of individual attribution dimension scores instead of a composite attribution index that sums across individual dimensions (Carver, 1989; Fincham \& Bradbury, 1992), we examined both in the present study. As all three attribution dimension indices were scored in the same direction (with higher scores reflecting attributions that are likely to be negatively related to satisfaction), a composite attribution index was computed by simply summing the locus, stability, and globality scores $(\alpha$ for wives $=.73$, for husbands $=.71$ ). This score therefore constitutes an index of relationship negative attributions.

\section{Results}

Consistent with past research and the rationale outlined in the introduction, separate analyses are reported for husbands and wives. Unless otherwise specified, the results reported pertain to the husbands $(n=96)$ and wives $(n=94)$ who provided complete data on all the variables investigated.

\section{Attributions, Depression, Self-Esteem, and Concurrent Marital Satisfaction}

Table 1 shows the concurrent correlations among the variables at Time 1 and Time 2. Several prior findings were replicated, including the association between marital satisfaction and depressive symptoms, self-esteem, and attributions. However, the depression-attribution association was inconsistent and varied across attribution dimensions and gender. As anticipated, the magnitude of the correlation between depression scores and self-esteem was moderate, supporting the decision to measure these two constructs independently.

We conducted regression analyses for husbands and for wives to determine whether depressive symptoms and self-esteem might account for the concurrent relation between marital satisfaction and attributions. Marital satisfaction served as the dependent variable and the three attribution dimensions, depression scores, and self-esteem served as predictor variables that were entered simultaneously into the regression equation. To test the hypothesis that the "third variables" (depression and self-esteem) account for the attribution-marital satisfaction relation, we computed the unique variance associated with the attribution dimensions. This variance is the amount $R^{2}$ would drop if the attribution dimensions were omitted and the regression equation was recomputed. We also computed the unique variance associated with depression and self-esteem.

Table 2 shows the $R^{2}$ associated with the regression equations for wives and husbands at Time 1 and Time 2 as well as the unique variance associated with the attribution dimensions and the variables of depression and self-esteem. The results are consistent across time and gender. Overall, the predictor variables accounted for a significant portion of the variance in marital satisfaction $(M=29.7 \%)$. In each equation, the attribution dimensions accounted for a significant portion of unique variance in satisfaction; hence the attribution-satisfaction relation does not simply reflect level of depressive symptoms or self-esteem.

Because it has been recommended that research reports include findings for both individual attribution dimensions and the attribution indices used in prior research (Carver, 1989; Fincham \& Bradbury, 1992), we computed an identical set of regression equations using the composite measure of causal attributions in place of the three individual attribution dimensions. We obtained the same pattern of results, and percentages of variance accounted for were very close to those reported in Table 2 (in no case was the difference greater than $3 \%$ ). 
Table 1

Concurrent Correlations Among Measures for Wives (Above Diagonal) and Husbands (Below Diagonal) at Time 1 and Time 2

\begin{tabular}{|c|c|c|c|c|c|c|c|}
\hline Measure & 1 & 2 & 3 & 4 & 5 & 6 & 7 \\
\hline \multicolumn{8}{|c|}{ Time 1} \\
\hline $\begin{array}{l}\text { 1. MAT } \\
\text { 2. BDI } \\
\text { 3. RSES } \\
\text { 4. Locus } \\
\text { 5. Stability } \\
\text { 6. Globality } \\
\text { 7. Composite }\end{array}$ & $\begin{array}{l}-\overline{38^{* *}} \\
.31^{*} \\
-.10 \\
-.38^{* *} \\
-.33^{* *} \\
-.37^{* *} \\
\end{array}$ & $\begin{array}{l}-.41^{* *} \\
-.56^{* *} \\
-.01 \\
.18 \\
.15 \\
.15 \\
\end{array}$ & $\begin{array}{l}.22 \\
-.56^{* *} \\
-.08 \\
-.15 \\
-.24 \\
-.14 \\
\end{array}$ & $\begin{array}{l}-.18 \\
.04 \\
.09 \\
- \\
.05 \\
.05 \\
.56^{* *} \\
\end{array}$ & $\begin{array}{l}-.44^{* *} \\
.20 \\
-.01 \\
.10 \\
-63^{* *} \\
.77^{* *}\end{array}$ & $\begin{array}{c}-.49^{* *} \\
.46^{* *} \\
-.22 \\
.17 \\
.55^{* *} \\
\overline{79^{* *}} \\
\end{array}$ & $\begin{array}{l}-.51^{* *} \\
.32^{* *} \\
-.06 \\
.60^{* *} \\
.75^{* *} \\
.80^{* *} \\
- \\
\end{array}$ \\
\hline \multicolumn{8}{|c|}{ Time 2} \\
\hline $\begin{array}{l}\text { 1. MAT } \\
\text { 2. BDI } \\
\text { 3. RSES } \\
\text { 4. Locus } \\
\text { 5. Stability } \\
\text { 6. Globality } \\
\text { 7. Composite }\end{array}$ & $\begin{array}{l}-\overline{37^{* *}} \\
.34^{* *} \\
-.02 \\
-.45^{* *} \\
-.35^{* *} \\
-.41^{* *}\end{array}$ & $\begin{array}{l}-.37^{* *} \\
-.55^{* *} \\
-.21 \\
.28^{*} \\
.31^{*} \\
.19\end{array}$ & $\begin{array}{c}.29^{*} \\
-.66^{* *} \\
-\overline{14} \\
-.33^{* *} \\
-.32^{* *} \\
-.26^{*}\end{array}$ & $\begin{array}{r}-.16 \\
-.07 \\
.17 \\
-.01 \\
-.14 \\
.44^{* *}\end{array}$ & $\begin{array}{l}-.32^{* *} \\
.16 \\
-.17 \\
.23 \\
.61^{* *} \\
.81^{* *}\end{array}$ & $\begin{array}{l}-.45^{* *} \\
.29^{*} \\
-.35^{* *} \\
.01 \\
.41^{* *} \\
.74^{* *}\end{array}$ & $\begin{array}{l}-.45^{* *} \\
.18 \\
-.16 \\
.64^{* *} \\
.74^{* *} \\
.70^{* *} \\
-\end{array}$ \\
\hline
\end{tabular}

Note. $\quad$ MAT $=$ Marital Adjustment Test (Locke \& Wallace, 1959); BDI = Beck Depression Inventory $($ Beck \& Beamesderfer, 1974); RSES = Rosenberg Self-Esteem Scale (Rosenberg, 1965).

${ }^{*} p<.01$ one-tailed. ${ }^{* *} p<.001$ one-tailed.

\section{Attributions, Depression, Self-Esteem, and Future Marital Satisfaction}

We conducted longitudinal analyses with the complete sample and with a subset of the sample that excluded persons who

Table 2

Variance in Marital Satisfaction Accounted for Overall and Unique Variance Associated With Attribution Dimensions and With Depression and Self-Esteem at Time 1 and Time 2

\begin{tabular}{|c|c|c|c|c|}
\hline \multirow[b]{2}{*}{ Predictors } & \multicolumn{2}{|c|}{ Time 1} & \multicolumn{2}{|c|}{ Time 2} \\
\hline & $R^{2}$ & $F$ & $R^{2}$ & $F$ \\
\hline \multicolumn{5}{|c|}{ Wives } \\
\hline Overall & .34 & $9.2^{* * *}$ & .30 & $7.7^{* * *}$ \\
\hline Attribution dimensions & .17 & $7.8^{* * *}$ & .16 & $6.9^{* * *}$ \\
\hline Locus & .01 & 1.7 & .02 & 2.7 \\
\hline Stability & .05 & $6.8^{* *}$ & .01 & 1.0 \\
\hline Globality & .02 & $2.9^{*}$ & .08 & $10.3^{* * * *}$ \\
\hline BDI and RSES & .06 & $3.7^{* *}$ & .06 & $4.0^{* *}$ \\
\hline BDI & .03 & $3.8^{*}$ & .04 & $4.7^{* *}$ \\
\hline RSES & .00 & $<1$ & .00 & $<1$ \\
\hline \multicolumn{5}{|c|}{ Husbands } \\
\hline Overall & .27 & $6.6^{* * *}$ & .28 & $7.1^{* * *}$ \\
\hline Attribution dimensions & .11 & $4.6^{* * *}$ & .12 & $4.9^{* * *}$ \\
\hline Locus & .01 & 1.0 & .01 & $<1$ \\
\hline Stability & .04 & $4.7^{* * *}$ & .06 & $6.9^{* * *}$ \\
\hline Globality & .01 & $<1$ & .00 & $<1$ \\
\hline BDI and RSES & .10 & $6.4^{* * *}$ & .07 & $4.6^{* *}$ \\
\hline BDI & .04 & $5.4^{* *}$ & .03 & $4.2^{* *}$ \\
\hline RSES & .01 & $<1$ & .01 & $<1$ \\
\hline
\end{tabular}

Note. $\quad$ BDI $=$ Beck Depression Inventory $($ Beck \& Beamesderfer, 1974); RSES = Rosenberg Self-Esteem Scale (Rosenberg, 1965)

${ }^{*} p<.10 .^{* *} p<.05 .^{* * *} p<.01$. initially reported depression or marital distress. Spouses were excluded if they met either of two criteria: a score below 100 on the MAT or a score above 10 on the BDI in the initial phase of the study. These criteria are widely used to distinguish distressed from nondistressed spouses (Locke \& Wallace, 1959) and to differentiate nondepressed persons from those who are depressed (Beck et al., 1988). Using these criteria, we excluded 13 husbands and 21 wives from the sample available for analysis. The restricted sample therefore consisted of wives $(n=73$; depression scores, $M=4.91, S D=3.01$; satisfaction scores, $M=$ $118.13, S D=17.14)$ and husbands $(n=83$; depression scores, $M$ $=4.0, S D=2.59$; satisfaction scores, $M=114.94, S D=18.91$ ) who were neither maritally distressed nor depressed at Time 1 .

Table 3 shows the correlations between the variables at Time 1 and Time 2. As anticipated, we found longitudinal relations between depression and self-esteem and later satisfaction. Therefore, we computed regression analyses to examine whether these longitudinal relations for depression and self-esteem might account for the longitudinal relations found for the attribution variables. Marital satisfaction at Time 2 served as the dependent variable and predictor variables were Time 1 measures of satisfaction, depression, self-esteem, and attributions. To examine whether attributions account for variance in the Time 2 satisfaction beyond that associated with initial satisfaction, depression, and self-esteem, we computed the unique variance associated with the predictor variables.

As shown in Table 4, for wives and husbands the Time 1 attribution dimensions accounted for a significant portion of unique variance in Time 2 satisfaction. This finding also obtained for wives in the restricted sample, but husbands' initial attributions were only marginally significant predictors of later satisfaction in the restricted sample. However, the magnitude of the relation between husbands' attributions and later satisfaction did not differ significantly in the two samples. These findings are particularly noteworthy in view of the high correlation 
Table 3

Longitudinal Correlations Between Measures at Time 1 and Time 2 for Wives and Husbands

\begin{tabular}{|c|c|c|c|c|c|c|c|}
\hline \multirow[b]{2}{*}{ Time 1} & \multicolumn{7}{|c|}{ Time 2} \\
\hline & 1 & 2 & 3 & 4 & 5 & 6 & 7 \\
\hline \multicolumn{8}{|c|}{ Wives } \\
\hline \multicolumn{8}{|l|}{ Full sample } \\
\hline 1. MAT & $.70^{* *}$ & -.10 & .14 & -.20 & $-.30^{*}$ & $-.29 *$ & $-.38^{* *}$ \\
\hline 2. BDI & $-.42^{* *}$ & $.54^{* *}$ & $-.48^{* *}$ & .02 & .16 & $.25^{*}$ & .20 \\
\hline 3. RSES & $.30^{*}$ & $-.40^{* *}$ & $.64^{* *}$ & .03 & -.06 & -.20 & -.11 \\
\hline 4. Locus & $-.30^{*}$ & .06 & .14 & $.44^{* *}$ & .15 & .19 & $.39^{* *}$ \\
\hline 5. Stability & -.20 & -.07 & -.03 & .16 & $.44^{*}$ & .24 & $.38^{* *}$ \\
\hline 6. Globality & $-.29^{*}$ & .15 & $-.25^{*}$ & .12 & $.26^{*}$ & $.48^{* * *}$ & $.42^{* *}$ \\
\hline 7. Composite & $-.37^{* *}$ & .07 & -.06 & $.33^{*}$ & $.39^{* *}$ & $.42^{* *}$ & $.55^{* *}$ \\
\hline \multicolumn{8}{|c|}{ Restricted sample } \\
\hline 1. MAT & $.67^{* *}$ & -.07 & .18 & -.16 & -.22 & -.25 & $-.32^{*}$ \\
\hline 2. BDI & -.11 & $.43^{* *}$ & $-.31^{*}$ & .02 & .16 & .15 & .16 \\
\hline 3. RSES & .12 & -.08 & $.44^{* *}$ & -.04 & .02 & -.12 & -.08 \\
\hline 4. Locus & $-.39 * *$ & .23 & .02 & $.44^{* *}$ & .08 & .21 & $.39^{* *}$ \\
\hline 5. Stability & -.19 & -.02 & -.07 & .09 & $.44^{* *}$ & $.20^{* *}$ & $.35^{*}$ \\
\hline 6. Globality & -.15 & .16 & -.19 & .14 & .21 & $.44^{* *}$ & $.41^{* *}$ \\
\hline 7. Composite & $-.35^{*}$ & .17 & -.11 & $.32^{*}$ & $.35^{*}$ & $.40^{* *}$ & $.54^{* *}$ \\
\hline \multicolumn{8}{|c|}{ Husbands } \\
\hline \multicolumn{8}{|l|}{ Full sample } \\
\hline 1. MAT & $.72^{* *}$ & $-.39 * *$ & $.27^{*}$ & .17 & $-.35^{* *}$ & $-.33^{* *}$ & $-.26^{*}$ \\
\hline 2. BDI & $-.38^{* *}$ & $.67^{* *}$ & $-.41^{* *}$ & -.12 & .15 & .20 & .11 \\
\hline 3. RSES & $.27^{*}$ & $-.46^{* *}$ & $.54^{* *}$ & .13 & -.15 & -.19 & -.10 \\
\hline 4. Locus & $-.28^{*}$ & .02 & .08 & $.49^{* *}$ & -.01 & -.05 & .22 \\
\hline 5. Stability & -.26 & .21 & -.11 & -.20 & $.37^{* *}$ & $.42^{* *}$ & $.29^{*}$ \\
\hline 6. Globality & $-.28^{*}$ & .18 & -.17 & -.07 & $.32^{* *}$ & $.46^{* *}$ & $.35^{* *}$ \\
\hline 7. Composite & $-.39^{* *}$ & .19 & -.09 & .13 & $.31^{*}$ & $.38^{* *}$ & $.41^{* *}$ \\
\hline \multicolumn{8}{|c|}{ Restricted sample } \\
\hline 1. MAT & $.63^{* *}$ & -.24 & .15 & .19 & $-.34^{* *}$ & $-.30^{*}$ & -.21 \\
\hline 2. BDI & -.04 & $.40^{* *}$ & -.18 & -.18 & .14 & .12 & .04 \\
\hline 3. RSES & .05 & $-.27^{*}$ & $.45^{* *}$ & .15 & -.20 & -.15 & -.09 \\
\hline 4. Locus & -.23 & -.01 & .14 & $.48^{* *}$ & -.01 & -.04 & .21 \\
\hline 5. Stability & -.28 & .06 & -.06 & -.18 & $.36^{* *}$ & $.40^{* *}$ & $.28^{*}$ \\
\hline 6. Globality & $-.31^{*}$ & .09 & -.17 & -.09 & $.34^{* *}$ & $.43^{* *}$ & $.34^{* *}$ \\
\hline 7. Composite & $-.39^{* *}$ & .06 & -.04 & .12 & $.32^{*}$ & $.36^{* *}$ & $.39^{* *}$ \\
\hline
\end{tabular}

Note. $\quad$ MAT $=$ Marital Adjustment Test (Locke \& Wallace, 1959); BDI = Beck Depression Inventory $($ Beck \& Beamesderfer, 1974); RSES = Rosenberg Self-Esteem Scale (Rosenberg, 1965).

${ }^{*} p<.01$ one-tailed. ${ }^{* *} p<.001$ one-tailed.

found between satisfaction scores in the two phases of the project, which greatly reduced the proportion of variance for which attribution dimensions could account. In sum, it appears that the set of attribution dimensions predicts later satisfaction for husbands and wives and that these longitudinal relations are not due to depression, self-esteem, or the presence of chronic disorder. $^{2}$

To investigate the role of individual attribution dimensions, we examined the unique variance associated with each. For husbands and wives and full versus restricted samples, the locus dimension alone accounted for unique variance in later satisfaction, a finding that most likely reflects the high correlation between stability and globality and the low correlation between these two dimensions and causal locus. As the locus dimension combined two separate ratings, we computed the unique variance associated with partner and self causal loci by substituting these two measures for the composite locus measure used in the regression equations. There was no change in the significance levels shown in Table 4 . For husbands, both partner, $F(1,88)=$
$4.4, p<.05$, and self, $F(1,88)=4.9, p<.05$, attribution loci predicted later satisfaction. Locating the cause in the partner was negatively associated with later satisfaction, whereas self-attributions for partner behavior were positively related to later satisfaction. For wives, only the self-attribution locus significantly predicted later satisfaction, $F(1,86)=6.2, p<.05$; self-attributions were again positively associated with later satisfaction.

Before interpreting these findings, it is important to consider whether marital satisfaction predicts later attributions. If this were the case, the data would be consistent with the view that marital satisfaction influences attributions. To examine this

\footnotetext{
${ }^{2}$ Regression analyses using the combined data from husbands and wives yielded similar results. However, husbands and wives do not provide independent data points and therefore combining their data in this manner can artificially inflate correlations. Consequently, the results are reported separately for husbands and wives.
} 
Table 4

Variance in Time 2 Satisfaction Accounted for Overall and Unique Variance Associated With Time 1 Satisfaction, Depression and Self-Esteem, and Attribution Dimensions

\begin{tabular}{|c|c|c|c|c|c|c|c|c|}
\hline \multirow{4}{*}{$\begin{array}{l}\text { Time 1 } \\
\text { predictors }\end{array}$} & \multicolumn{8}{|c|}{ Marital satisfaction (Time 2) } \\
\hline & \multicolumn{4}{|c|}{ Full sample } & \multicolumn{4}{|c|}{ Restricted sample } \\
\hline & \multicolumn{2}{|c|}{ Husbands } & \multicolumn{2}{|c|}{ Wives } & \multicolumn{2}{|c|}{ Husbands } & \multicolumn{2}{|c|}{ Wives } \\
\hline & $R^{2}$ & $F$ & $R^{2}$ & $F$ & $R^{2}$ & $F$ & $R^{2}$ & $F$ \\
\hline Overall & .57 & $19.8^{* * *}$ & .58 & $19.9^{* * *}$ & .46 & $10.7^{* * *}$ & .54 & $12.8^{* * *}$ \\
\hline Marital satisfaction & .30 & $62.2^{* * *}$ & .30 & $60.9^{* * *}$ & .30 & $42.7^{* * *}$ & .32 & $44.9^{* * *}$ \\
\hline BDI and RSES & .02 & 1.7 & .04 & $4.1^{*}$ & .01 & $<1$ & .00 & $<1$ \\
\hline BDI & .01 & 2.3 & .01 & 2.6 & .00 & $<1$ & .00 & $<1$ \\
\hline RSES & .00 & $<1$ & .01 & 1.6 & .00 & $<1$ & .00 & $<1$ \\
\hline Attribution dimensions & .05 & $3.6^{* *}$ & .06 & $4.1^{* *}$ & .05 & $2.4^{*}$ & .08 & $3.9^{* *}$ \\
\hline Locus & .04 & $9.3^{* * *}$ & .04 & $8.8^{* * *}$ & .03 & $4.5^{* *}$ & .07 & $10.4^{* * *}$ \\
\hline Stability & .00 & $<1$ & .00 & $<1$ & .00 & $<1$ & .00 & $<1$ \\
\hline Globality & .01 & 1.1 & .01 & 1.7 & .00 & $<1$ & .02 & 2.2 \\
\hline
\end{tabular}

Note. $\quad$ BDI $=$ Beck Depression Inventory $($ Beck \& Beamesderfer, 1974); RSES $=$ Rosenberg Self-Esteem Scale $($ Rosenberg, 1965)

${ }^{*} p<.10 .{ }^{* *} p<.05 .{ }^{* * *} p<.01$.

possibility, we adopted the same strategy used in the analyses described above. That is, we computed a regression equation for each of the three attribution dimensions. In each case, the Time 2 attribution dimension served as the dependent variable and the corresponding dimension score at Time 1 was entered into the equation together with the depression, self-esteem, and marital satisfaction scores.

Table 5 shows that husbands' satisfaction accounted for significant unique variance in the equations used to predict later locus and stability attribution dimensions and a marginally significant amount of variance in the equation predicting the globality dimension. Although the level of significance changed for the stability and globality attributions in the restricted sample, the relations did not differ significantly for husbands in the two samples. In contrast, Time 1 satisfaction did not predict later attributions for wives in either the full or restricted samples. The differing patterns of results obtained for husbands and wives suggest that the nature of the causal relation between attributions and satisfaction may differ across gender. Specifically, the data for wives are consistent with the

Table 5

Unique Variance in Prediction of Time 2 Attribution Dimensions From Corresponding Time 1 Dimension, Depression and Self-Esteem, and Marital Satisfaction

\begin{tabular}{|c|c|c|c|c|c|c|c|c|}
\hline \multirow{4}{*}{$\begin{array}{c}\text { Time } 1 \\
\text { predictors }\end{array}$} & \multicolumn{8}{|c|}{ Attribution dimensions } \\
\hline & \multicolumn{4}{|c|}{ Full sample } & \multicolumn{4}{|c|}{ Restricted sample } \\
\hline & \multicolumn{2}{|c|}{ Husbands } & \multicolumn{2}{|c|}{ Wives } & \multicolumn{2}{|c|}{ Husbands } & \multicolumn{2}{|c|}{ Wives } \\
\hline & $R^{2}$ & $F$ & $R^{2}$ & $F$ & $R^{2}$ & $F$ & $R^{2}$ & $F$ \\
\hline \multicolumn{9}{|c|}{ Locus (Time 2) } \\
\hline Locus & .25 & $32.3^{* * *}$ & .16 & $17.8^{* * *}$ & .22 & $23.5^{* * *}$ & .18 & $15.2^{* * *}$ \\
\hline BDI and RSES & .00 & $<1$ & .00 & $<1$ & .01 & $<1$ & .01 & $<1$ \\
\hline Marital satisfaction & .04 & $4.6^{* *}$ & .02 & 2.1 & .04 & $4.0^{* * *}$ & .00 & $<1$ \\
\hline \multicolumn{9}{|c|}{ Stability (Time 2) } \\
\hline Stability & .06 & $6.7^{* *}$ & .12 & $13.0^{* * *}$ & .06 & $5.6^{* *}$ & .14 & $12.1^{* * *}$ \\
\hline BDI and RSES & .00 & $<1$ & .01 & $<1$ & .02 & $<1$ & .01 & $<1$ \\
\hline Marital satisfaction & .04 & $4.9^{* *}$ & .01 & 1.2 & .04 & $3.7^{*}$ & .00 & $<1$ \\
\hline \multicolumn{9}{|c|}{ Globality (Time 2) } \\
\hline Globality & .13 & $15.6^{* * *}$ & .13 & $15.3^{* * *}$ & .12 & $11.9^{* * *}$ & .14 & $12.1^{* * *}$ \\
\hline BDI and RSES & .00 & $<1$ & .01 & $<1$ & .00 & $<1$ & .01 & $<1$ \\
\hline Marital satisfaction & .03 & $3.1^{*}$ & .00 & $<1$ & .03 & 2.6 & .01 & $<1$ \\
\hline
\end{tabular}

Note. $\quad$ BDI $=$ Beck Depression Inventory $($ Beck \& Beamesderfer, 1974); RSES = Rosenberg Self-Esteem Scale (Rosenberg, 1965).

${ }^{*} p<.10{ }^{* *} p<.05 .^{* * *} p<.01$. 
view that attributions influence later satisfaction, whereas the husbands' data are consistent with a bidirectional causal relation between attributions and marital satisfaction.

Following Carver's (1989) and Fincham and Bradbury's (1992) recommendations, we also investigated the longitudinal relations between attributions and satisfaction using the composite index of attribution. We computed a similar set of regression equations substituting the composite score for the three individual attribution dimensions. Unlike the results concerning concurrent correlations, we obtained a different pattern of findings. Specifically, the wives' attribution composite did not predict their later satisfaction in either the complete or restricted samples. Initial marital satisfaction did not predict wives' later attributions in either sample. In contrast, husbands' initial attributions tended to increase the variance accounted for in later satisfaction in the complete, $\Delta R^{2}=.02, F(1,95)=$ $3.5, p<.07$, and restricted, $\Delta R^{2}=.04, F(1,82)=5.0, p<.05$, samples. However, initial satisfaction did not predict the husbands' later attributions.

Finally, we found limited evidence that was consistent with a causal relation between depression and marital satisfaction. To investigate this issue, we conducted regression analyses in which we used Time 1 depression to predict Time 2 satisfaction with initial satisfaction entered into the regression equation. We computed analogous regressions using Time 2 depression as a dependent variable. For wives, earlier depression increased the variance accounted for in later satisfaction, $\Delta R^{2}=.02, F(1,93)$ $=3.98, p<.05$, a finding that did not obtain for the restricted sample. However, initial satisfaction did not predict later depression. In contrast, husbands' initial depression did not predict Time 2 satisfaction, whereas initial satisfaction increased the variance accounted for in later depression in the full sample, $\Delta R^{2}=.02, F(1,95)=3.93, p<.05$, and was a marginally significant predictor in the restricted sample, $\Delta R^{2}=.03, F(1$, $82)=3.1, p<.09$. When attribution dimensions were entered into the regression equation, none of the findings discussed above remained significant.

\section{Discussion}

\section{Replication of Prior Findings}

Although the primary purpose of the present study was to examine the longitudinal relation between attributions and marital satisfaction, the study also provided the opportunity to replicate concurrent correlates of marital satisfaction. Consistent with prior findings, higher levels of depressive symptoms were inversely related to marital satisfaction and self-esteem was positively related to marital satisfaction. With the exception of wives' self-esteem at Time 1 , the correlations were statistically significant for husbands and for wives at both assessment periods. Although gender differences might have been expected in view of such factors as differential rates of depression, degree of self-criticism, and valuing of intimate relationships across husbands and wives, we found no such differences in the relation between depression and marital satisfaction or in the relation between self-esteem and satisfaction.

\section{Attributions Vary as a Function of Concurrent Marital Satisfaction}

As expected, the inverse relation between attributions for partner behavior and marital satisfaction emerged for husbands and wives at both assessments. In view of the finding that attribution dimensions accounted for a significant portion of unique variance in wives' and husbands' marital satisfaction when depression and self-esteem were included along with the attribution dimensions in regression analyses that predicted satisfaction, the attribution-satisfaction link does not appear to be an artifact of depression or self-esteem.

Our results extend prior findings in two important respects. First, they build on Fletcher et al.'s (1990) findings for dating couples by showing that depression does not account for the attribution-relationship happiness link in married couples. In a similar vein, they extend Fincham et al.s (1989) results by demonstrating that they apply to causal attributions and to husbands. Second, these are the first data to rule out self-esteem as a variable that might account for the association between attributions and concurrent marital satisfaction.

Before turning to the longitudinal findings, it is worth noting that the data on concurrent relations among the variables also address an issue of increasing importance to marital researchers, namely, the relation between depression and marital satisfaction. Because "it is not yet clear to what extent ... attributions mediate the association between depression and marital distress" (Gotlib \& Hooley, 1988, p. 565), it should be noted that depression accounted for statistically significant proportions of unique variance in the regression equations predicting concurrent satisfaction for husbands and wives at both assessments (see Table 2). These findings suggest that, in a community sample, causal attributions do not play a mediating role in the link between depression and concurrent marital distress, although they clearly play a moderating role in this relation.

The importance of these concurrent findings is emphasized by their theoretical and applied significance. At the theoretical level, they answer the critical question of whether the attribution patterns documented in the marital literature constitute a marital phenomenon per se. By ruling out depression and selfesteem as factors that might account for the attribution-satisfaction link, the present findings provide support for the role accorded to attributions in recent theoretical analyses of marital dysfunction. At the applied level, the results suggest that interventions designed to alleviate spousal depression may not be sufficient to reverse the maladaptive attributions associated with marital distress.

\section{Causal Attributions Are Likely to Influence Marital Satisfaction}

The longitudinal relations between attributions and satisfaction also replicate and extend prior findings. As in Fincham and Bradbury's (1987) study, wives' initial attributions predicted their marital satisfaction 12 months later. Thus, we have obtained consistent evidence to suggest that causal attributions may influence wives' marital satisfaction. The present findings indicate further that this relation cannot be attributed to depression, self-esteem, or chronic individual or marital distress.

The present study provides the first data documenting a longitudinal relation between attributions and husbands' satisfaction. Husbands' attributions, similar to their wives', predicted later satisfaction independently of depression, self-esteem, or initial disorder. The positive finding regarding husbands' attributions contrasts with Fincham and Bradbury's (1987) results. 
The reason for this discrepancy is unclear, although it could be due to a number of factors, including the use of a far larger sample in the present study. In any event, for both wives and husbands, this study provides data consistent with a central assumption of recent theoretical analyses of marital dysfunction, namely, that attributions influence marital satisfaction. The significance of these findings is emphasized by the relative stability of the variables studied, a circumstance that most likely reflects the investigation of couples married for some time (mean length of marriage $=9.4$ years).

However, the data are also consistent with a causal relation in which husbands' marital satisfaction influences later attributions. It is therefore quite possible that a reciprocal causal relation exists between attributions and marital satisfaction. In view of this possibility, it is important to note that the power of attributions at time $n$ to predict satisfaction at time $n+1$ may result from the fact that these attributions are simply a reflection of marital satisfaction at time $n-1 .^{3}$ Data from a longitudinal study that includes at least three assessment phases are therefore needed before stronger conclusions can be drawn about the longitudinal relation, and possible causal nature of the relation, between attributions and marital satisfaction. The importance of multiwave, longitudinal data are also emphasized by the need to investigate the temporal relation between attributions and satisfaction using different time lags. It is quite possible that any effects these variables have on each other might occur over longer or shorter intervals. Thus, the absence of any information pertaining to the optimal lag for attributions and satisfaction to influence each other renders the present findings all the more noteworthy.

Two intriguing patterns emerge when the concurrent and longitudinal relations between attributions and satisfaction are compared. First, analysis of individual attribution dimensions and the composite attribution index yields the same pattern of findings in relation to concurrent satisfaction. However, we found fewer longitudinal relations using the composite attribution index. These findings emphasize the importance of avoiding premature use of composite indices in the investigation of attribution dimensions (Bradbury \& Fincham, 1990).

Second, the locus dimension was not significantly related to concurrent satisfaction for either husbands or wives but correlated significantly with later marital satisfaction. Moreover, locus accounted for unique variance in later satisfaction. These findings are consistent with recent behavioral research showing that changes in marital satisfaction are best predicted by behaviors that are not related to concurrent satisfaction (Gottman \& Krokoff, 1989). The present results suggest that perceived causal locus may be a risk factor for marital discord. Specifically, the locus dimension may play a role in initiating marital discord but not necessarily in maintaining the discord. Although intriguing, the findings regarding causal locus should be interpreted with caution as the magnitude of concurrent and longitudinal correlations involving causal dimensions and satisfaction did not differ statistically.

Because attributional models of depression and of marital distress both predict a correlation with causal locus, the absence of concurrent relations involving this dimension seems surprising. As regards depression, it is important to recall that the attribution pattern associated with this disorder tends to occur only when the person makes attributions concerning his or her own behavior and not the behavior of others (e.g., Garber \& Hollon, 1980). In the present study, the stimuli for which attribution judgments were made consisted of partner behaviors, a circumstance that might account for the lack of association between this dimension and depression scores. It is still possible that attributions for relationship events that clearly result from the attributor's behavior are related to depression. An important task for future research is to examine the relations among depression, marital satisfaction, theself-attributions typically studied in depression research, and the attributions assessed in marital studies that usually involve partner behavior.

The lack of a concurrent relation between causal locus and marital satisfaction is more puzzling. However, this causal dimension has yielded the least robust association with marital satisfaction, leading to inconsistent results across and within studies. Such inconsistency most likely reflects difficulties in conceptualizing the nature of this dimension in both basic attribution research (cf. Ross, 1977) and marital research (cf. Fincham, 1985). Nonetheless, our attempt to investigate partner and self loci relative to each other was useful in predicting later marital satisfaction and therefore deserves further study.

Although not central to the present study, the data also speak to a possible causal relation between depression and marital satisfaction, a topic that is gaining increasing attention (e.g., Beach et al., 1990; Gotlib \& Hooley, 1988). Again an interesting pattern of findings emerged that differed across gender; wives' initial depression predicted later satisfaction whereas husbands' initial satisfaction predicted later depression. Thus, some evidence was obtained that is consistent with a bidirectional causal relation between depression and marital satisfaction. However, these findings should be interpreted cautiously because the finding for wives did not occur in the restricted sample and the relation found for husbands was only marginally significant in this sample. The significance of these findings also assumes continuity between mild forms of depressive symptoms and depression as a clinical syndrome, an assumption that remains controversial.

\section{Final Comments}

We have noted several cautions in discussing the results of this study. However, two additional factors require emphasis when interpreting the present findings. First, longitudinal data are correlational and therefore can only provide data consistent with a particular causal interpretation. Ideally, attributions and marital satisfaction should be manipulated to determine their effects on each other. However, ethical and practical restraints make such manipulations extremely difficult in this domain. Second, the collection of data by mail is a potential threat to the integrity of the data. It assumes that spouses answer questions

\footnotetext{
${ }^{3}$ In view of this observation, it is worth noting that husbands' satisfaction accounted for a significant increase in $R^{2}$ in the equations used to predict later locus and stability attribution dimensions and a marginally significant increase in $R^{2}$ in the equation predicting the globality dimension. In contrast, Time 1 satisfaction did not predict later attributions for wives in either the full or restricted samples. The differing patterns of results obtained for husbands and wives suggest that the nature of the longitudinal relation between attributions and satisfaction may differ across gender.
} 
sincerely and follow instructions in the absence of supervision. Although the sincerity of self-report cannot be guaranteed under any conditions, the replication of several prior findings provides some support for these assumptions. In view of their limitations, the present results are best view as suggestive findings that need to be replicated in a multiwave longitudinal study that spans a period when significant things happen in the marriage (e.g., the first few years of marriage, the birth of a child).

Notwithstanding these cautionary notes, the present study is among the first to provide data consistent with recent theoretical analyses of cognition in close relationships in which attributions are accorded a central role. Specifically, it shows that the attributions studied in the marital literature are not simply the function of a general pattern of attributions that result from depression or self-esteem and provides data that are consistent with the widely assumed effects of attributions on marital satisfaction. It therefore provides some support for the more difficult task of investigating the processes whereby attributions influence satisfaction, an endeavor that emphasizes the need for data relating attributions to marital behavior.

\section{References}

Baucom, D. H. (1987). Attributions in distressed relations: How can we explain them? In S. Duck \& D. Perlman (Eds.), Heterosexual relations, marriage, and divorce (pp. 177-206). London: Sage.

Baucom, D. H., Notarius, C. I., Burnett, C. K., \& Haefner, P. (1990). Gender differences and sex-role identity in marriage. In F. D. Fincham \& T. N. Bradbury (Eds.), The psychology of marriage (pp. 150171). New York: Guilford Press.

Baucom, D. H., Sayers, S. L., \& Duhe, A. (1989). Attributional style and attributional patterns among married couples. Journal of Personality and Social Psychology, 56, 596-607.

Baucom, D. H., Sayers, S. L., \& Sher, T. G. (1990). Supplementing behavioral marital therapy with cognitive restructuring and emotional expressiveness training: An outcome investigation. Journal of Consulting and Clinical Psychology, 58, 636-645.

Beach, S. R. H., Sandeen, E., \& O'Leary, K. D. (1990). Depression in marriage. New York: Guilford Press.

Beck, A. T., \& Beamesderfer, A. (1974). Assessment of depression: The depression inventory. In P. Pichot (Ed.) Modern problems in pharmacopsychiatry (pp. 151-169). Basel, Switzerland: Karger.

Beck, A. T., Steer, R. A., \& Garbin, M. G. (1988). Psychometric properties of the Beck Depression Inventory: Twenty-five years of evaluation. Clinical Psychology Review, 8, 77-100.

Bradbury, T. N., \& Fincham, F. D. (1990). Attributions in marriage: Review and critique. Psychological Bulletin, 107, 3-33.

Bradbury, T. N., \& Fincham, F. D. (1992). Attributions and behavior in marital interaction. Journal of Personality and Social Psychology, 63, 613-628.

Carver, C. S. (1989). How should multifaceted constructs be tested? Issues illustrated by self-monitoring, attributional style, and hardiness. Journal of Personality and Social Psychology, 56, 577-585.

Carver, C. S., \& Gannellen, R. J. (1983). Depression and components of self-punitiveness: High standards, self-criticism, and over-generalization. Journal of Abnormal Psychology, 92, 330-337.

Crowther, J. H. (1985). The relationship between depression and marital adjustment: A descriptive study. The Journal of Nervous and Mental Disease, 173, 227-231.

Depue, R. A., \& Monroe, S. M. (1986). Conceptualization and measurement of human disorder in life stress research: The problem of chronic disturbance. Psychological Bulletin, 99, 36-51.
Doherty, W. J. (1982). Attribution style and negative problem solving in marriage. Family Relations, 31, 201-205.

Epstein, N. (1982). Cognitive therapy with couples. The American Journal of Family Therapy, 10, 5-16.

Fincham, F. D. (1985). Attributional processes in distressed and nondistressed couples: 2 . Responsibility for marital problems. Journal of Abnormal Psychology, 94, 183-190.

Fincham, F. D., \& Beach, S. R. (1988). Attribution processes in distressed and nondistressed couples: 5 . Real versus hypothetical events. Cognitive Therapy and Research, 5, 505-514.

Fincham, F. D., Beach, S. R. H., \& Bradbury, T. N. (1989). Marital distress, depression, and attributions: Is the marital distress-attribution association an artifact of depression? Journal of Consulting and Clinical Psychology, 57, 768-771.

Fincham, F. D., Beach, S. R., \& Nelson, G. (1987). Attributional processes in distressed and nondistressed couples: 3 . Causal and responsibility attributions for spouse behavior. Cognitive Therapy and $R e-$ search, 11, 71-86.

Fincham, F. D., \& Bradbury, T. N. (1987). The impact of attributions in marriage: A longitudinal analysis. Journal of Personality and Social Psychology, 53, 481-489.

Fincham, F. D., \& Bradbury, T. N. (1988). The impact of attributions in marriage: An experimental analysis. Journal of Social and Clinical Psychology, 7, 147-162.

Fincham, F. D., \& Bradbury, T. N. (1991). Cognition in marriage: A program of research on attributions. Advances in Personal Relationships, 2, 159-203.

Fincham, F. D., \& Bradbury, T. N. (1992). Assessing attributions in marriage: The Relationship Attribution Measure. Journal of Personality and Social Psychology, 62, 457-468.

Fincham, F. D., Bradbury, T. N., \& Beach, S. R. (1990). To arrive where we began: Cognition in marital therapy. Journal of Family Psychology, 4, 167-184.

Fitzpatrick, M. A. (1988). Between husband and wife: Communication in marriage. Beverly Hills, CA: Sage.

Fletcher, G. J. O., Fincham, F. D., Cramer, L., \& Heron, N. (1987). The role of attributions in the development of dating relationships. Journal of Personality and Social Psychology, 53, 510-517.

Fletcher, G. J. O., Fitness, J., \& Blampied, N. M. (1990). The link between attributions and happiness in close relationships: The roles of depression and explanatory style. Journal of Social and Clinical Psychology, 9, 243-255.

Garber, J., \& Hollon, S. D. (1980). Universal versus personal helplessness: Belief in uncontrollability or incompetence. Journal of Abnormal Psychology, 89, 56-66.

Gotlib, I. H., \& Hooley, J. M. (1988). Depression and marital functioning. In S. Duck (Ed.), Handbook of personal relationships: Theory; research and interventions (pp. 543-570). Chichester, England: Wiley.

Gotlib, I. H., \& McCabe, S. B. (1990). Marriage and psychopathology. In F. D. Fincham \& T. N. Bradbury (Eds.), The psychology of marriage (pp. 226-257). New York: Guilford Press.

Gottman, J. M., \& Krokoff, L. J. (1989). Marital interaction and marital satisfaction: A longitudinal view. Journal of Consulting and Clinical Psychology, 57, 47-52.

Harvey, J. H. (1987). Attributions in close relationships: Research and theoretical developments. Journal of Social and Clinical Psychology, $5,420-434$.

Ickes, W. (1985). Sex-role influences on compatibility in relationships. In W. Ickes (Ed.), Compatible and incompatible relationships (pp. 187-208). New York: Springer-Verlag.

Ickes, W. (1988). Attributional styles and the self-concept. In L. Y. Abramson (Ed.), Social cognition and clinical psychology (pp. 6697). New York: Guilford Press.

Ickes, W., \& Layden, M. A. (1978). Attributional styles. In J. H. Harvey, W. Ickes, \& R. F. Kidd (Eds.), New directions in attribution research (Vol. 2, pp. 121-157). Hillsdale, NJ: Erlbaum. 
Locke, H. J., \& Wallace, K. M. (1959). Short marital adjustment and prediction tests: Their reliability and validity. Marriage and Family Living, 21, 251-255.

Miller, P. C., Lefcourt, H. M., Holmes, J. G., Ware, E. E., \& Saleh, W. E. (1986). Marital locus of control and marital problem solving. Journal of Personality and Social Psychology, 51, 161-169.

Noller, P. (1987). Nonverbal communication in marriage. In D. Perlman \& S. Duck (Eds.), Intimate relationships: Development, dynamics, and deterioration (pp. 123-147). Beverly Hills, CA: Sage.

Olson, J. M., \& Ross, M. (1985). Attribution: Past, present and future. In J. H. Harvey \& G. Weary (Eds.), Attribution: Basic issues and applications (pp. 282-311). San Diego, CA: Academic Press.

Rempel, J. K., Holmes, J. G., \& Zanna, M. P. (1985). Trust in close relationships. Journal of Personality and Social Psychology, 49, 95112.

Robins, C. J. (1988). Attributions and depression: Why is the literature so inconsistent? Journal of Personality and Social Psychology, 54, 880-889.

Rosenberg, M. (1965). Society and adolescent self-image. Princeton, NJ: Princeton University Press.

Ross, L. (1977). The intuitive psychologist and his shortcomings. In L. Berkowitz (Ed.), Advances in experimental social psychology (Vol.10, pp. 173-220). San Diego, CA: Academic Press.

Rubin, Z. (1970). Measurement of romantic love. Journal of Personality and Social Psychology, 16, 265-273.

Seligman, C., Fazio, R. H., \& Zanna, M. P. (1980). Effects of salience of extrinsic rewards on liking and loving. Journal of Personality and Social Psychology, 38, 453-460.
Shaver, K. G. (1985). The attribution of blame: Causality, responsibility, and blameworthiness. New York: Springer-Verlag.

Silber, E., \& Tippett, J. (1965). Self-esteem: Clinical assessment and measurement validation. Psychological Reports, 16, 1017-1071.

Sillars, A. L. (1985). Interpersonal perception in relationships. In W. Ickes (Ed.), Compatible and incompatible relationships (pp. 277305). New York: Springer-Verlag.

Taylor, S. E., \& Koivumaki, J. H. (1976). The perception of self and others: Acquaintanceship, affect, and actor-observer differences. Journal of Personality and Social Psychology, 33, 403-406.

Vanfossen, B. E. (1986). Sex differences in depression: The role of spouse support. In S. E. Hobfoll (Ed.), Stress, social support, and women (pp. 78-89). Washington, DC: Hemisphere.

Weiss, R. L., \& Heyman, R. (1990). Marital distress and therapy. In A. S. Bellack, M. Hersen, \& A. E. Kazdin (Eds.), International handbook of behavior modification (2nd ed., pp. 475-501). New York: Plenum Press.

Zautra, A. J., Guenther, R. T., \& Chartier, G. M. (1985). Attributions for real and hypothetical events: Their relation to self-esteem and depression. Journal of Abnormal Psychology, 94, 530-540.

Zautra, A. J., \& Reich, J. W. (1983). Life events and perceptions of life quality: Developments in a two-factor approach. Journal of Community Psychology, 11, 121-132.

Received April 11, 1991

Revision received May 4, 1992 Accepted September 15, 1992 